\title{
L’Hôpital-Général de Québec et le soin des aliénés (1717-1845)
}

\section{John R. Porter}

Volume 44, 1977

URI : https://id.erudit.org/iderudit/1007127ar

DOI : https://doi.org/10.7202/1007127ar

Aller au sommaire du numéro

Éditeur(s)

Les Éditions Historia Ecclesiæ Catholicæ Canadensis Inc.

ISSN

0318-6172 (imprimé)

1927-7067 (numérique)

Découvrir la revue

Citer cet article

Porter, J. R. (1977). L’Hôpital-Général de Québec et le soin des aliénés (1717-1845). Sessions d'étude - Société canadienne d'histoire de l'Église catholique, 44, 23-55. https://doi.org/10.7202/1007127ar

Tous droits réservés @ Les Éditions Historia Ecclesiæ Catholicæ Canadensis Inc., 1977
Ce document est protégé par la loi sur le droit d'auteur. L'utilisation des services d'Érudit (y compris la reproduction) est assujettie à sa politique d'utilisation que vous pouvez consulter en ligne.

https://apropos.erudit.org/fr/usagers/politique-dutilisation/ 


\section{L'Hôpital-Général de Québec et le soin des aliénés (1717-1845)}

"Notre hôpital est composé de trois grandes salles, vingt quatre loges pour les insensées ( $\mathrm{sic}$ ), un beau et grand pensionnat et quelques appartements pour les personnes âgées, infirmes et qui aiment la vie retirée.

"Nous sommes hors de la ville et éloignées d'une demi lieue, sur le bord d'une belle rivière, ce qui contribue à la santé, car nos invalides et nos religieuses vivent pour l'ordinaire très longtemps 1 ».

Cet extrait d'une lettre envoyée en 1831 par la supérieure de l'Hôpital-Général de Québec à celle du monastère des Augustines de Dieppe résume bien les différentes vocations remplies à l'époque par les religieuses. Celles-ci étaient alors sensiblement les mêmes que sous le régime français. On se rappellera en effet qu'après avoir fait l'acquisition de l'ancien monastère des Récollets, $\mathrm{M}^{\mathrm{gr}}$ de Saint-Vallier y fondait en 1692 un hôpital général dont il confia la gérance à des religieuses augustines détachées de l'Hôtel-Dieu de Québec. La nouvelle institution était analogue à celles du même nom établies dans toutes les grandes villes de France à partir de 1662 suite à un édit royal. Elle se consacrerait donc au soin des pauvres, des vieillards et des invalides ${ }^{2}$.

Soucieux de répondre à d'autres besoins de la colonie, l'évêque de Québec devait augmenter la tâche de ses protégées en 1717, les chargeant de la garde des aliénées ${ }^{3}$. C'est ainsi qu'il donna suite

1 Archives de l'Hôpital-Général de Québec (dorénavant AHGQ), Copies de lettres adressées à Nos Communautés de France (1758-1935), pp. 28-29.

2 Pour plus de détails sur la nature de l'institution et son évolution jusqu'à la Conquête, voir Micheline D'AllaIRE, L'Hôpital-Général de Québec, 1692-1764, Montréal, Fides [1971], pp. 1-50.

3 Pour assurer la survie de l'institution, il allait les autoriser en 1725 à ouvrir un pensionnat pour jeunes filles qui devait exister jusqu'en 1868 . 
à des demandes réitérées de l'intendant Bégon ${ }^{4}$ en faisant construire cette année-là un bâtiment comprenant quatre loges voûtées ${ }^{5}$ :

Il Se trouvoit dans ce pays plusieurs personnes attaquées de folie, Et notre hopital toujours le refuge de ceux qui n'Etoient pas furieux n'ayant pas d'Endroits pour Enfermer les autres. Monseigneur voyant $\mathrm{La}$ peine des familles résolut de faire bâtir une maison de force Et y fit travailler avec tant d'activité qu'en Six mois Elle fut En Etat d'y mettre en Sureté les plus furieux... 6

$M^{g r}$ de Saint-Vallier ne destinait cette construction qu'aux seules aliénées. Il considérait que «la retraitte des fols du Genre masculin doit estre reservée a des hopitaux riches et non pas a un hopital aussi pauvre que celui de Quebec l'est presentement »7. Selon lui, les religieuses ne seraient pas en mesure de soigner ellesmêmes les aliénés de sexe masculin et devraient avoir recours à « des Valets forts pour les dompter», ce qui entraînerait des coûts trop élevés pour les moyens de l'institution ${ }^{8}$.

En 1720, le gouverneur Vaudreuil et l'intendant Bégon recommandèrent au ministre de la Marine la construction d'un nouveau bâtiment, destiné celui-là aux aliénés ${ }^{9}$. Le projet fut accepté l'année suivante ${ }^{10}$. En 1723, la Cour accorda à l'Hôpital-Général une rente annuelle de $£ 2000$ à condition qu'il se charge du soin des pauvres et des.aliénés des deux sexes ${ }^{11}$. Évaluée à $£ 2200$, la nouvelle construction fut achevée à l'automne de la même année ${ }^{12}$ suivant des plans et devis exécutés par l'architecte Gaspard Chaussegros de Léry en $1721^{13}$ (ill. 1). Attenante à celle qu'avait fait construire $\mathrm{M}^{\mathrm{gr}}$ de Saint-Vallier en 1717, elle comprenait quatre loges voûtées en pierre, était couverte de bardeaux et chauffée par un poêle central. Chaque loge disposait d'une petite ouverture vitrée et grillagée pour laisser pénétrer la lumière ${ }^{14}$.

4 Archives publiques du Canada, Ottawa (donéavant APC), AC, Série C. $11^{\mathrm{a}}$, vol. 41 , pp. $262-262 \mathrm{v}$.

5 Loc. cit. et ibid., vol. 43, pp. 383-383v.

6 AHGQ, Annales [ Suite des annales des Religieuses de La miséricorde de jesus. Etablie à notre Dame des anges près Québec »] (1709-1729), p. 37.

7 APC, AC, Série C.11a, vol. 43, pp. 385-385v.

8 Loc. cit.

9 lbid., vol. 42, pp. 10v-11.

10 Ibid., vol. 43 , p. 4.

11 Ibid., vol. 44, p. 286 ; AHGQ, Annales (1709-1729), p. 46.

12 APC, AC, Série C.11", vol. 45, p. 81v.

13 Ibid., vol. 43, pp. 383-383v.

14 Voir l'illustration 1. 


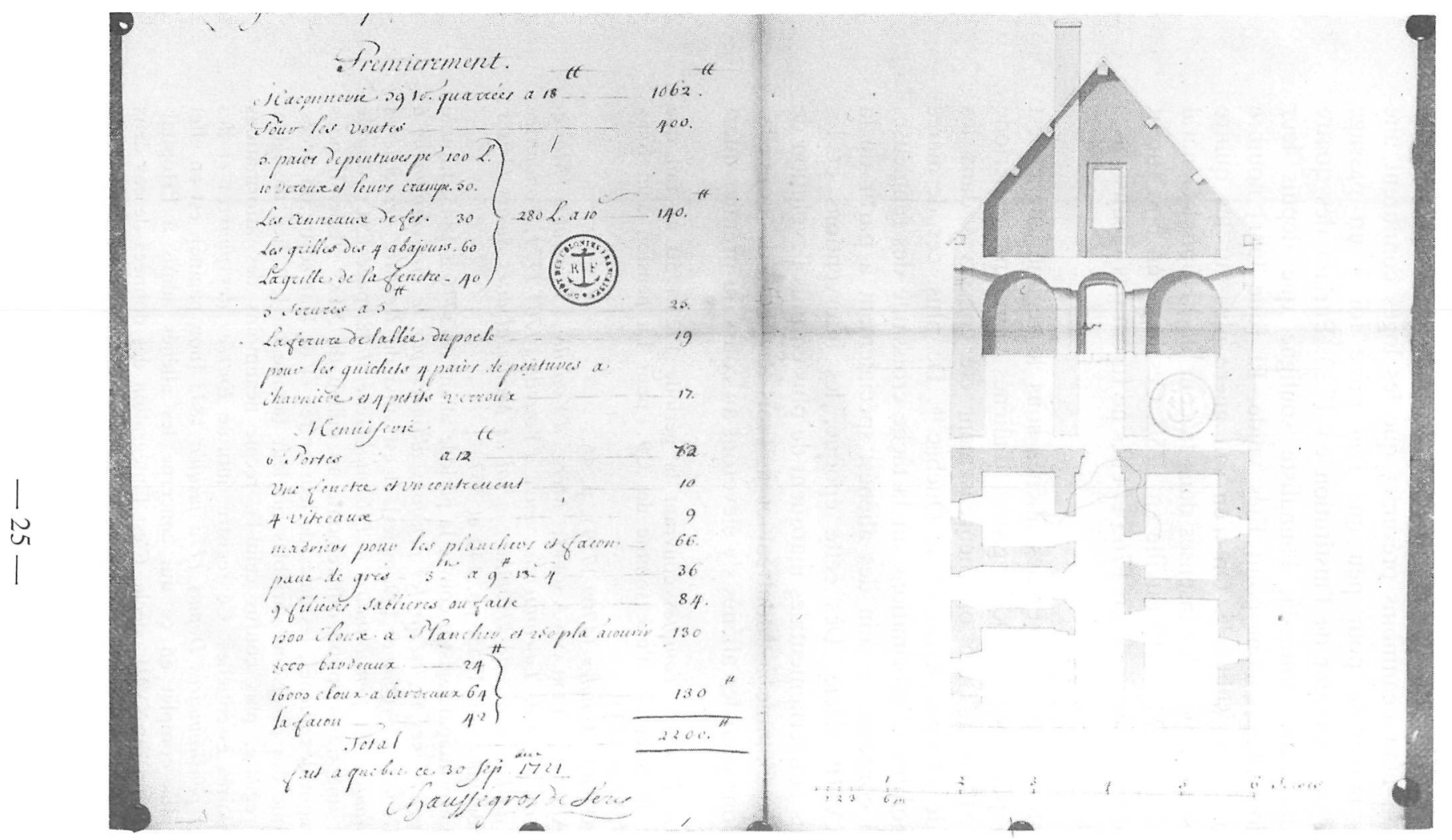

1. Gaspard Chaussegros DE LÉRY, Estimations Pour une Maison a faire pour enfermer Les foux a Lhopital general de Quehec. - 30 septembre 1721. Duplicata envoyé en France le 8 octobre 1721. 35,6 $\times 46 \mathrm{~cm}$. Archives publiques du Canada, Ottawa. 
On ne sait presque rien sur les aliénés des deux sexes internés dans les huit loges de l'Hôpital-Général sous le régime français ${ }^{15}$. Même si l'on n'a pas conservé de registre des aliénés couvrant cette période, on peut néanmoins présumer que les loges connurent une utilisation maximale pour peu que l'on prête foi à un passage révélateur des Annales de l'institution en 1723. Parlant des quatre loges bâties cette année-là, l'annaliste souligne que depuis leur construction elles «n'ont point Etés vuide, Et [que leur] nombre même n'a jamais sufit ${ }^{16}$. On n'en sait guère plus sur les quatre loges construites pour les insensés dans la cour de l'Hôpital-Général de Montréal par Mère d'Youville en 1750. Ces loges en bois furent détruites dans un incendie en 1765 et elles ne furent pas reconstruites faute de moyens ${ }^{17}$.

L'histoire des loges et des aliénés sous le régime anglais est beaucoup plus étoffée. Des registres d'aliénés couvrant la période allant de 1776 à 1845 ont heureusement été conservés dans les archives de l'Hôpital-Général de Québec ${ }^{18}$. De plus, ces dernières recèlent nombre d'informations sur la tâche croissante des religieuses en ce qui concerne le soin des aliénés, spécialement à partir de la fin du XVIII e siècle. Dès cette époque, les interventions et les législations gouvernementales marquent de plus en plus l'évolution de l'institution. Comme à Montréal et à Trois-Rivières, de nouvelles constructions pour les aliénés s'y élèveront au cours du premier quart

15 Le Livre de comptes couvrant la période 1727-1750 ne fait que mentionner la réception d'une somme de $£ 9$ «pour La pension d'un fou» en 1732-1733 (p. 133).

16 AHGQ, Annales (1709-1729), p. 46.

17 Albertine Ferland-Angers, Mère d'Youville, Vénérable MarieMarguerite du Frost de Lajemmerais, veuve d'Youville, 1701-1771, Fondatrice des Saurs de la Charité de l'Hôpital-général de Montréal dites Saurs Grises, Montréal, Beauchemin, 1945, pp. 140 et 357.

18 Le principal registre couvre la période allant de 1776 à 1845. Intitulé Registre des Aliénés reçus sur les pensions allouées par le Gouvernement à l'Hôpital Général de Québec [39 pages], il est suivi du Registre des Aliénés reçus en qualité de pensionnaire à l'Hôpital-Général [8 pages]. Ce double registre est une transcription qui remonte au milieu du XIXe siècle. Il nous fournit le nom des aliénés, les dates de leur entrée et de leur sortie ou décès, de même que des précisions variables sur leur famille ou leur lieu d'origine. Un autre registre, plus confus celui-là, recèle néanmoins des informations complémentaires essentielles. Ce registre, intitulé Entrées des pauvres et des Demoiselles pensionnaires Depuis 1773 jusqu'à 1833 [non paginé], est en effet beaucoup plus complet en ce qui concerne les aliénés admis à l'HôpitalGénéral à la fin du XVIII' siècle. C'est l'intégration des données de ces deuX registres qui nous a servi de base pour tout ce qui a trait à la fréquentation des loges de l'institution. 
du $\mathrm{XIX}^{\mathrm{e}}$ siècle. À des loges de type conventionnel construites en 1802 , s'ajouteront en 1818 des " cellules morales 》 plus susceptibles de faciliter la réhabilitation de malades moins gravement atteints. L'architecte François Baillairgé jouera un rôle important dans l'élaboration du devis de ces nouvelles cellules, bâties suite à des pressions médicales. Des pressions analogues amèneront également, en 1822-1823, la réfection des anciennes loges pour les rendre plus salubres. Par ailleurs, les résultats d'une enquête commandée à cette époque par le gouvernement et touchant les institutions de Québec, Montréal et Trois-Rivières nous fourniront nombre de précisions sur le taux de fréquentation, le traitement et le système d'internement des aliénés dans ces trois villes. Toutefois, la recommandation principale du rapport du comité d'enquête (1824), c'est-à-dire la construction d'un asile central plus conforme aux nouvelles techniques de traitement des maladies mentales, ne trouvera un début d'application qu'en 1845, avec la mise sur pied de l'Asile temporaire de Beauport. C'est cette institution qui rassemblera les aliénés de toute la province à l'automne de 1845 , mettant ainsi un point final au traitement des aliénés à l'Hôpital-Général de Québec.

Nous ignorons combien d'années après la Conquête les loges furent à nouveau accessibles aux aliénés. Néanmoins l'année 1776 semble marquer une reprise des opérations. Les registres des aliénés commencent cette année-là et mentionnent l'internement de sept personnes. Or nous savons qu'à l'époque il ne restait du régime français que six loges sur les huit d'origine. En effet, après la Conquête, comme ces dernières tombaient en ruines, les religieuses en avaient fait réparer six ${ }^{19}$. Séparées de l'édifice principal de l'Hôpital-Général par un ruisseau, elles étaient situées à l'opposé de la façade. Un plan tracé par Jeanne-Geneviève de Saint-Ours en 1785 illustre leur emplacement exact (ill. 2). Un détail de ce même plan nous montre une vue schématique de l'édifice des loges. Celui-ci comporte six fenêtres, ce qui confirme l'existence de six loges à l'époque (ill. 3 ).

De 1776 à 1800 exclusivement, les loges accueillirent 45 aliénés, soit 32 hommes et 13 femmes. Le plus souvent, ces derniers étaient internés suite à une requête du gouverneur (ou d'une autorité militaire) ou d'un médecin, et parfois à leur demande conjointe. Exceptionnellement, un curé, un juge de paix, un parent ou le

19 Voir Monseigneur de Saint-Vallier et l'Hôpital Général de Québec, Québec, C. Darveau, 1882, p. 478 et Pierre-Georges Roy, Les asiles d'aliénés, dans Bulletin des recherches historiques, vol. I, no 9 (septembre 1895), p. 143. 


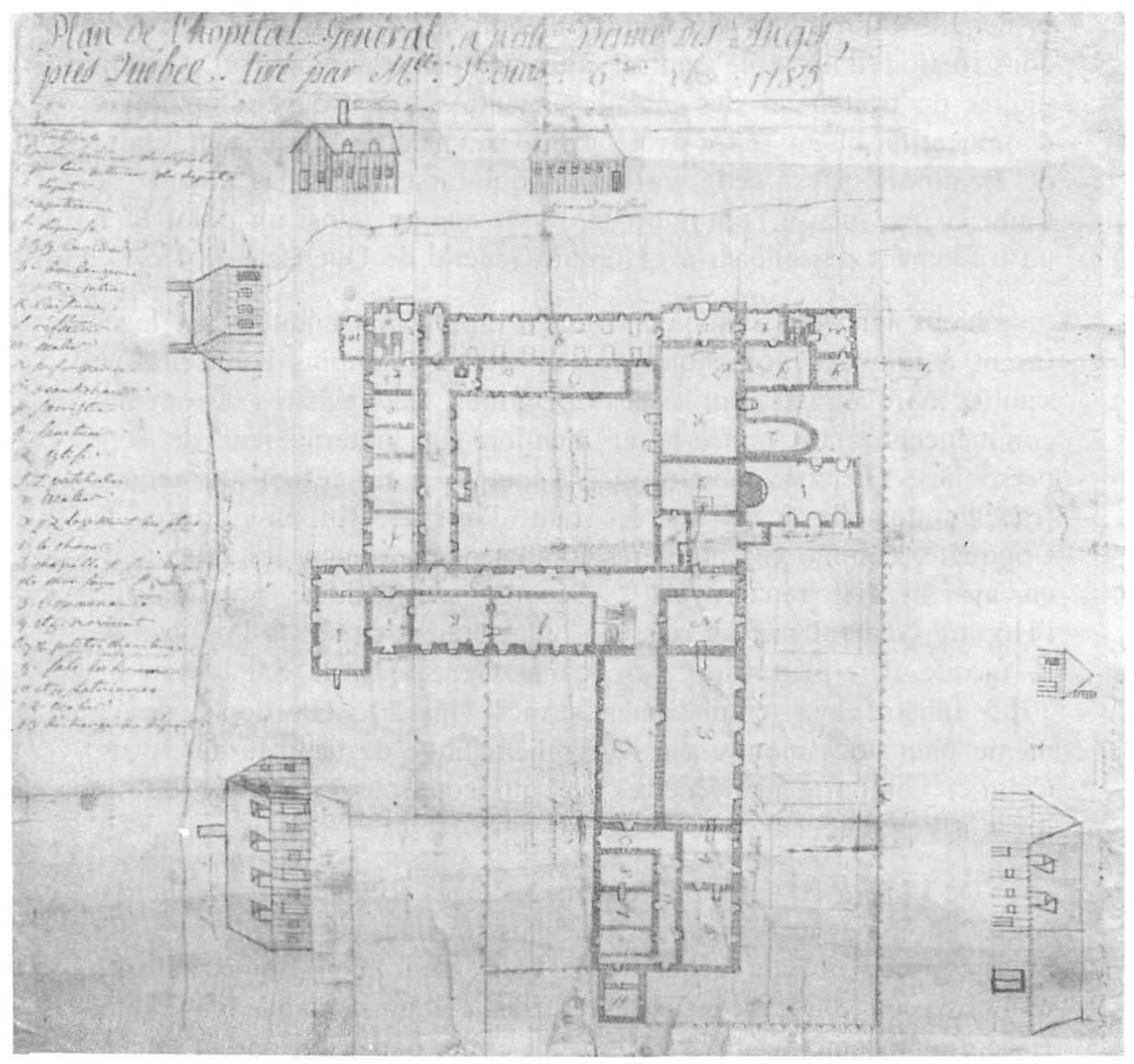

2. Jeanne-Geneviève DE SAINT-Ours, Plan de l'hopital Général, à notre Dame Des Anges, près Québec. - 6 décembre 1785. $52,1 \times 54 \mathrm{~cm}$. Archives de l'Hôpital-Général de Québec, Québec. 


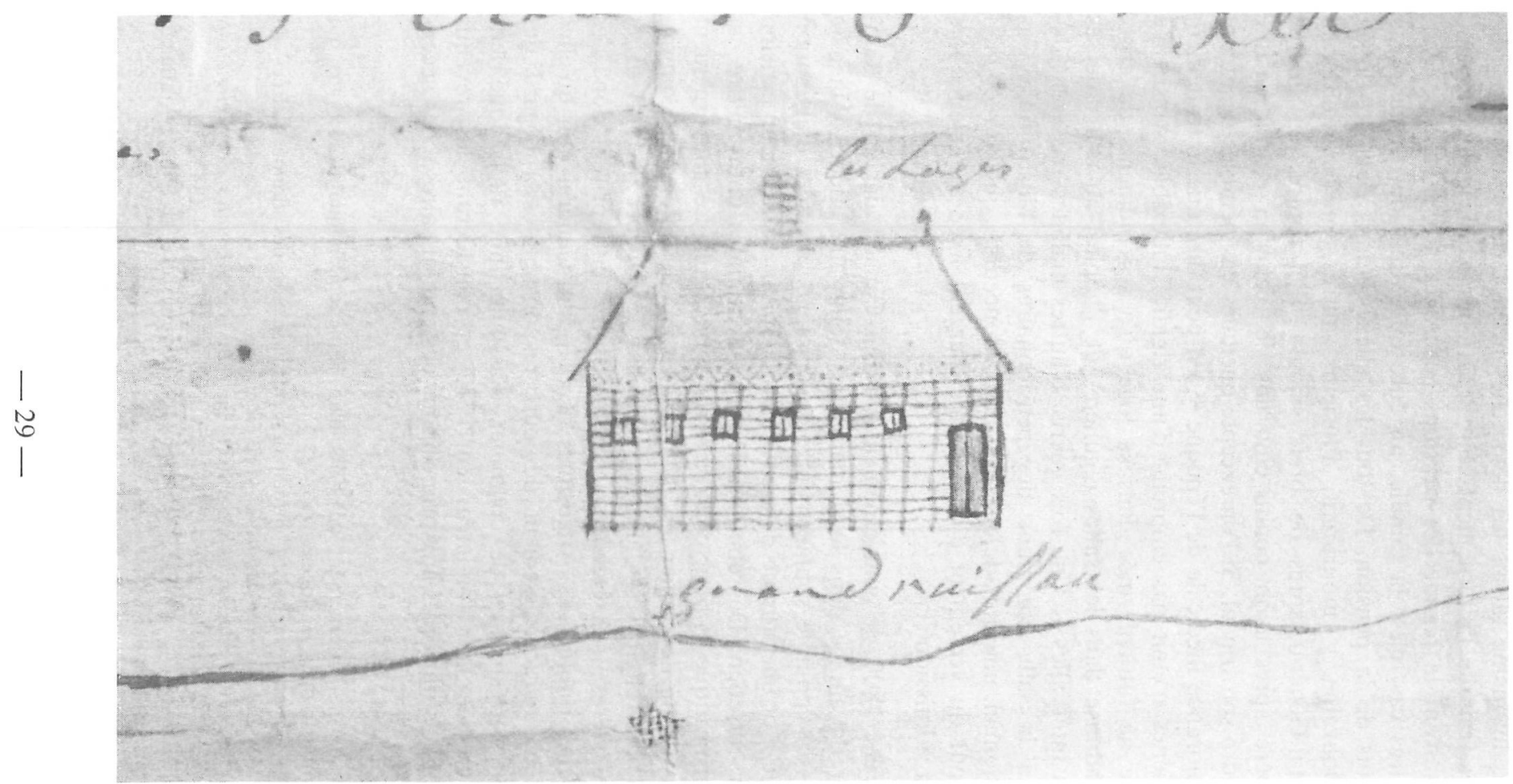

3. Les Loges. - Détail de la figure 2. 
malade lui-même faisait les démarches nécessaires. Dans $80 \%$ des cas, les frais de l'internement étaient assumés par le gouvernement, mais suivant le régime des pensions accordées aux invalides. Dans les autres cas, c'est la famille, un curé ou le malade qui défrayait les coûts de la pension. De tous les aliénés admis dans les loges, une douzaine y moururent. Plusieurs autres, guéris, quittèrent l'Hôpital-Général après de brefs séjours. Par contre, un interné fut libéré après avoir connu cinq ans de réclusion et put ensuite reprendre son travail. Si l'on excepte quelques cas pénibles découlant de l'ignorance médicale de l'époque ${ }^{20}$, on peut dire que le traitement des aliénés n'était pas empreint d'une rigidité inflexible. Ainsi, une malade ne fut enfermée dans sa loge qu'à ses moments de crise, étant admise dans les salles régulières de l'hôpital au cours de ses «bons intervalles». Une fois guéris, d'autres malades passèrent des loges à la salle commune des pensionnaires de l'institution. Cas exceptionnel, une malade eut droit aux « douceurs » qu'elle réclamait en retour du versement d'une somme d'argent fixée à cet effet lors de son admission ${ }^{21}$.

Vers 1800 , le gouvernement du Bas-Canada décida de s'impliquer davantage dans le domaine des soins aux aliénés. Un acte fut passé «pour le soulagement des personnes affectées d'aliénation mentale » et une somme d'argent fut votée pour assurer leur pension et leur entretien. Des commissaires furent nommés pour mettre cet acte en pratique et pour contrôler son application. Le gouvernement avait convenu de confier les aliénés aux soins de différentes communautés de religieuses dans les districts de Québec, Montréal et Trois-Rivières ${ }^{22}$. À Québec, les commissaires entreprirent donc des démarches auprès des Augustines de l'Hôpital-Général afin qu'elles acceptent un accroissement de leurs responsabilités à l'égard des aliénés ${ }^{23}$. Désireuses de continuer d'assumer une tâche que leur avait confiée leur fondateur en 1717 et considérant les revenus additionnels inhérents aux propositions des commissaires, elles acceptèrent ${ }^{24}$ :

20 V.g., l'internement en 1799 d'un jeune épileptique de 19 ans qui devait mourir dans les loges.

21 Ce paragraphe est principalement basé sur des données tirées du registre des Entrées des pauvres..., o.p. cit.

22 AHGQ, Journal (1825-1867), pp. 121-122; Annales des Religieuses Hospitalières de la Miséricorde de Jésus..., tome III (1794-1843), p. 64.

23 De 1800 à 1845,237 aliénés ( 126 hommes et 111 femmes) allaient être admis à l'Hôpital-Général.

24 Monseigneur de Saint-Vallier..., op. cit., p. 478 ; AHGQ, Journal du dépôt, tome I (1692-1909), p. 182. 
En conséquence du consentement de la Com ${ }^{\text {té }}$ les fondements d'une nouvelle Maison de force furent jetés au commencement du mois de mai [1802] dans laquelle douze loges furent pratiquées, celle que nous avions ci-devant n'en contenait que six : ce fut le 4 octobre que quelques unes des personnes de cet état [aliénés] y furent placés à la solde de la Commission... 25

Cette Maison [...] est en pierre [et] couverte en bois [...]. L'intérieur de la bâtisse est divisée en 12 cellules ou loges qui ont chacune 9 pieds quarrés sur 9 pieds de haut; elles sont doublées en planches de pin; le plafond est recouvert en maconnerie; cette précaution paraît avoir été prise en cas d'incendie en dehors des loges. Un corridor de 6 à 7 pieds de large se trouve entre les deux rangées de cellules; aux extrémités de ce corridor, il y a deux grandes fenêtres dont l'ouverture [sert] à renouveler l'air ; c'est aussi dans ce corridor qu' [est] le poele qui [chauffe] les cellules ${ }^{26}$.

Le plancher des loges était en pin tandis que le passage entre les cellules était pavé en pierre. Partant du poêle, un long tuyau parcourait ce passage. Pour l'accès de la lumière, chaque cellule disposait d'un œil-de-bœuf analogue à ceux qu'on utilisait à l'époque sur le pont des vaisseaux ${ }^{27}$. Nous savons également que dans chaque loge il y avait un tour par lequel les gardiens des aliénés leur donnaient leur nourriture depuis le corridor séparant les cellules ${ }^{28}$. L'emplacement des loges était à proximité du cimetière des pauvres de l'Hôpital-Général, comme en témoigne un détail d'une carte tracée par Joseph Bouchette en 1815 (ill. 4).

Les commissaires fixèrent le per diem de chacun des aliénés à 1 sol et 1 denier par jour. Les religieuses considéraient cette

25 AHGQ, Annales..., tome III (1794-1843), p. 64. Des 18 loges, 12 étaient règle générale occupées par des hommes et 6 par des femmes. Voir AHGQ, Jouinal (1760-1825), p. 348.

26 AHGQ, Notes diverses, 1686-1866, pp. 196-197. Les dimensions exactes des cellules étaient les mêmes que celles construites sous le régime français, i.e., 8 pieds de longueur sur 7 pieds et demi de largeur, et 8 pieds de hauteur. Voir AHGQ, Journal (1760-1825), p. 350.

27 AHGQ, Journal (1760-1825), pp. 348 et 350.

28 En 1812, un aliéné brisa le tour de sa loge et le médecin attaché à l'hôpital dut envoyer des soldats pour le placer, non sans peine, dans une autre loge. L'aliéné brisa à nouveau son tour et les religieuses réclamèrent encore à la commission l'envoi de soldats dans la crainte qu'il ne s'échappe et ne cause des dégâts sérieux. Voir AHGQ, Dossier "Divers documents», chemise "Aliénés»: Lettre de Sœur Sainte-Hélène, dépositaire, aux Commissaires, 27 octobre 1812. 


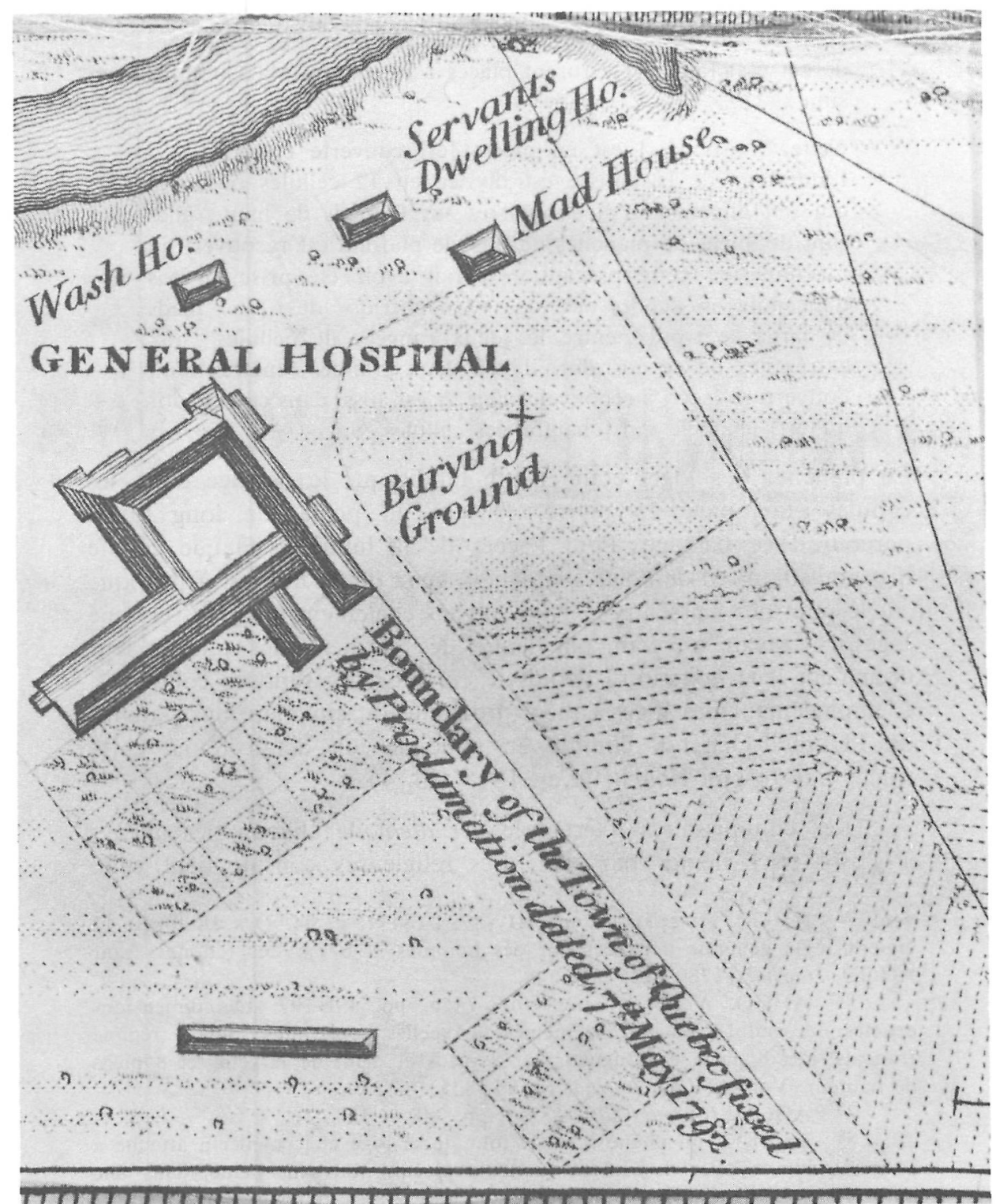

4. Joseph Bouchette, General Hospital. - Détail de la «Topographical map of the Province of Lower Canada...» (section : «City of Quebec »). 1815. Archives publiques du Canada, Ottawa. 
pension comme très modique compte tenu du coût des denrées alimentaires et des biens nécessaires au bon soin des aliénés. Il leur semblait même que dans ces conditions, leurs opérations seraient probablement déficitaires. Elles dressèrent d'ailleurs l'état de leurs dépenses quotidiennes pour illustrer leurs pertes :

Treize personnes occupaient annuellement les loges aux frais de la commission, mangeant par jour :

\begin{tabular}{|c|c|}
\hline $\begin{array}{l}13 \text { lbs de pain à } 6^{d} \text { sa } \\
\text { une livre chacune }\end{array}$ & $\begin{array}{l}\text { avoir } \\
\text { "“ }\end{array}$ \\
\hline 13 lbs de bœuf à $6^{\mathrm{d}}$ & “ \\
\hline
\end{tabular}

L'entretien journalier du linge, couvertes, paillasses et ustensilles pour leur service à 6 ? $0-6-6$

Par jour le bois nécessaire pour chauffer deux poëles à $2 / 6 \quad 0-5-0$

$$
£ 1-4-6
$$

Outre les réparations locatives, ou menues aux loges, les faire nettoyer, les hommes employés à les servir et autres objets évalués, nous recevions pour ces dépenses de la Commission pour 13 personnes

$1 / 1$ chaque

$0-14-1$

Ainsi perte journellement $\quad £ 0-10-5^{\text {d } 29}$

Tirant conclusion de cette évaluation négative, les religieuses n'hésitèrent pas à réclamer à diverses reprises des compensations de la part des commissaires pour amortir leurs pertes :

L'objet de la Législature et des Commissaires en plaçant ainsi ces personnes aliénées sous nos soins, n'avait point en vue de surcharger la Com té, au contraire de nous payer libéralement d'autant que les soins particuliers que nous en prenions étaient gratis, ce fut cette considération qui nous détermina à faire en plusieurs occasions des représentations afin d'obtenir des indemnités qui nous furent toujours accordées, mais sans être suffisantes pour combler le déficit entre les allouances et les dépenses que nous faisions pour cet objet ${ }^{30}$.

En 1814 , le per diem de l'aliéné passa de 1 sol et 1 denier à 2 sols ${ }^{31}$. Les sommes versées par les commissaires étaient bien sûr conformes au degré de fréquentation des loges, ce qui explique

29 AHGQ, Annales..., tome III (1794-1843), pp. 63-65.

30 Ihid., p. 65.

31 AHGQ, Journal (1760-1825), pp. 345 et 347. 
des variations sensibles des montants reçus par les religieuses ${ }^{32}$. De 1800 à 1824, un montant total de $£ 16518$ (cours de la province du Bas-Canada) fut versé aux religieuses pour le soin des aliénés ${ }^{33}$.

Dans le traitement physique et moral de ces derniers, les religieuses suivaient les instructions des médecins nommés à cet effet par le gouvernement ${ }^{34}$. En 1816, l'un d'eux, le docteur William Hackett, soumit un important mémoire au gouverneur, Sir John Sherbrooke :

M'ayant fait l'honneur de me nommer comme Medecin et Chirurgien des Malades du Gouvernement dans l'HôpitalGénéral, je crois de mon devoir de ne pas différer un seul instant de mettre sous vos yeux ce qui me paroit demander impérieusement l'attention, l'assistance et l'interposition de la Législature, afin de mettre cette partie de l'Institution appropriée pour l'accommodement des aliénés sur un pied préférable à celui sur lequel elle est actuellement ; sinon, elle doit rester ce qu'elle a été par le passé, un receptacle de maniaques sans permettre aux médecins de mettre en usage, dans son enceinte, les moyens que la science et l'expérience recommandent pour la guérison de cette terrible maladie.

La bâtisse en elle-même n'est nullement convenable : basse et confinée comme elle est, les vapeurs nuisibles qui sortent des personnes de cette classe, et qui indépendamment d'autres causes, sont particulières à cette maladie, vous frappent immédiatement en entrant dans cette enceinte. Ceci ne doit pas être attribué à aucun manque de la part des Dames de l'Institution (...) mais cela vient de l'erreur fondamentale de la conformation même de la batisse qui me paroit n'avoir été construite qu'en vue d'une seule espèce de folie, savoir : celle arrivée au degré de furie, sans même qu'on ait prévu la possibilité d'une convalescence par une cour ou un jardin attaché à la dite bâtisse ${ }^{35}$.

32 Voir, par exemple, AHGQ, Livre des comptes (1804-1825), pp. 10 [1804-1805] et 76 bis [1811-1812]; Journal de la Dépense et recette depuis 1808 jusqu'à 1827 , pp. $65-65$ bis [7 avril 1823], 67 bis [ 6 septembre 1823] et 69 [24 novembre 1823].

33 AHGQ, Journal (1760-1825), p. 345. En 1803, les religieuses refusèrent une offre du gouvernement d'ouvrir une maison de correction à l'HôpitalGénéral. AHGQ, Actes capitulaires, tome I (1699-1822), p. 175.

34 AHGQ, Notes diverses, 1686-1866, p. 197.

35 AHGQ, Journal (1760-1825), pp. 351-352. Le $\mathrm{D}^{\mathrm{r}}$ Hackett quitta son poste auprès des malades de l'Hôpital-Général en 1825 , alors qu'il s'embarqua pour les Indes. Il fut remplacé par les Docteurs Joseph Parent et Joseph Painchaud. 
Les suites de ce mémoire ne se firent guère attendre. Le 25 février 1817, $\mathbf{M}^{\mathrm{gr}}$ Joseph Octave Plessis, évêque de Québec, écrivait aux religieuses de l'Hôpital-Général pour leur faire part des activités des commissaires : "Voilà les commissaires des fous qui se remuent : ils doivent présenter ce soir à la chambre d'Assemblée, de concert avec ceux de Montréal et des Trois-Rivières, une pétition tendante à obtenir de l'argent pour réparation et augmentation des loges ${ }^{36}$. Le même jour, les commissaires ${ }^{37}$ avaient informé les religieuses de leur projet d'ériger une construction destinée aux "personnes qui paroissent susceptibles de recouvrer leur raison » et avaient sollicité leur accord ${ }^{38}$. Suivant les conseils de $\mathbf{M}^{\mathrm{gr}}$ Plessis, les Augustines répondirent favorablement aux commissaires, mais avec des réserves ${ }^{39}$. $\mathrm{M}^{\mathrm{gr}}$ Plessis se méfiait des empiètements des commissaires et ne voulait pas que les religieuses renoncent à leurs droits ${ }^{40}$. En effet, la construction projetée devait s'élever à l'extrémité nord de la façade de l'Hôpital-Général, sur l'emplacement des anciennes latrines, partie intégrante de l'édifice (ill. 2 et 5 ).

Une somme de $£ 2500$ fut votée, principalement pour la construction de six «cellules morales » destinées à accueillir des "aliénés dont la disposition n'était pas d'une nature furieuse " 41 . Une partie de cette somme devait servir à la construction d'un puisard et d'un canal longeant la façade de l'hôpital et se déchargeant dans la rivière Saint-Charles après avoir traversé les lieux communs ${ }^{42}$. Les commissaires publièrent un appel d'offres en ce

36 AHGQ, Dossier «Différentes lettres», document no 96 : Lettre de Mgr J.O. Plessis, évêque de Québec, à Mère Sainte-Hélène, supérieure de l'Hôpital-Général de Québec (25 février 1817).

37 Joseph Planté, Thomas Wilson, Louis Montizambert et William Holmes.

38 AHGQ, Dossier «Différentes lettres», document no 100 : Lettre des Commissaires aux religieuses de l'Hôpital-Général [25 février 1817].

39 Ibid., document no 99 : Copie d'une lettre des religieuses de l'Hôpital-Général aux Commissaires [25 février 1817].

40 Ibid., document no 96 : op. cit.; no 97 : Lettre de Mgr J.O. Plessis, évêque de Québec, à la supérieure de l'Hôpital-Général (16 février 1817); no 98 : Lettre de Mgr J.O. Plessis, évêque de Québec, à la supérieure de l'Hôpital Général (4 février 1817).

41 AHGQ, Notes diverses, 1686-1866, p. 198.

$42 \mathrm{Ce}$ "canal» ou égout devait mesurer 300 pieds de longueur et assurer une plus grande salubrité aux loges. AHGQ, Journal (1760-1825), p. 349. 


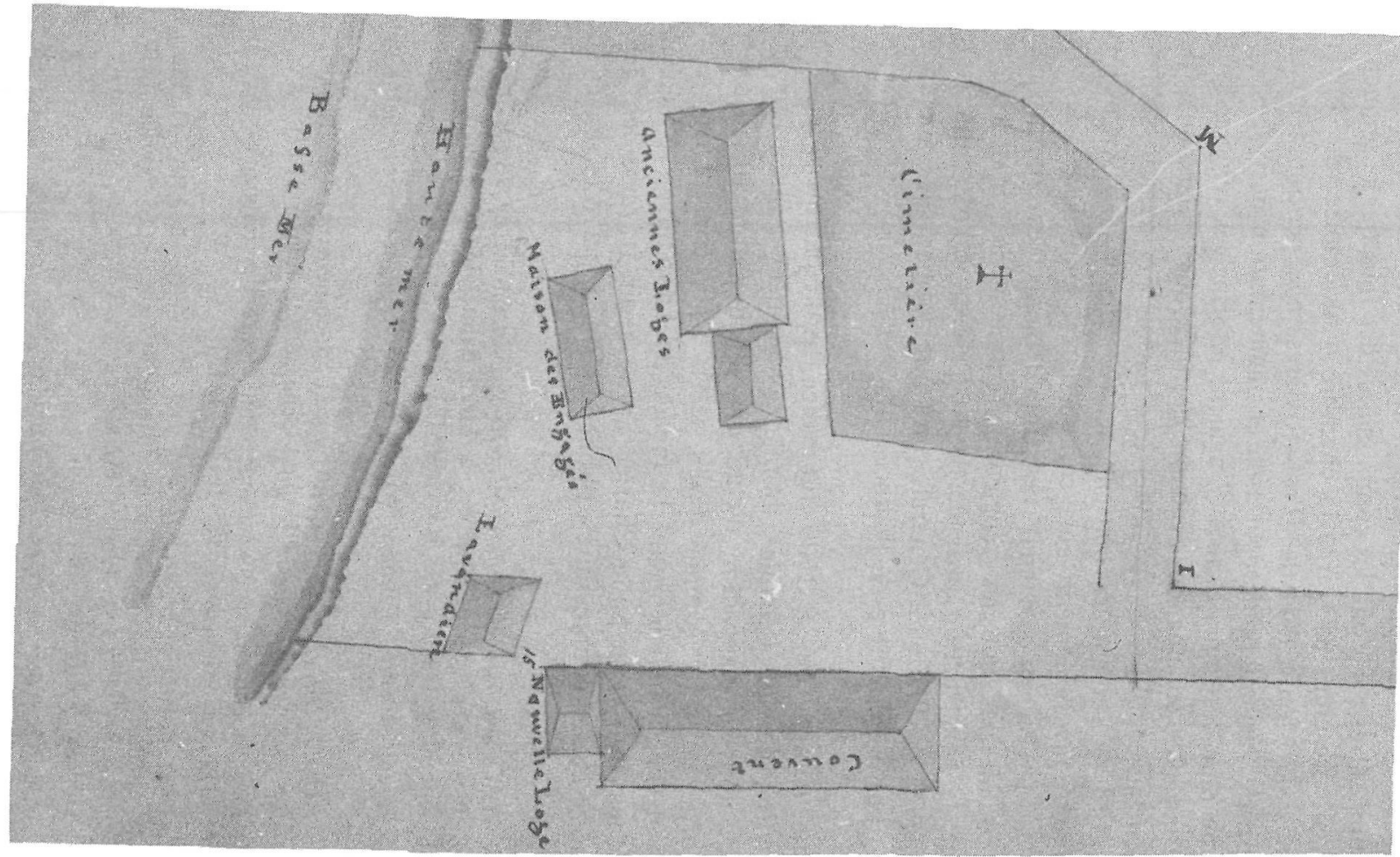

5. Jean-Baptiste Larue, [Plan d'un projet de prolongation de la rue de l'Hôpital Général jusqu'à la rivière StCharles]. - Détail. 31 juillet 1827. $56 \times 76 \mathrm{~cm}$. Archives de la ville de Québec, Québec. 
sens dans la Gazette de Québec du 28 mai 1818 et déposèrent les plans pour examen au parloir du dépôt de l'Hôpital-Général ${ }^{43}$.

Le 22 juin, l'entrepreneur maçon Charles Touchette présenta une soumission de $£ 599$ pour la construction du puisard et du canal en pierres voûtées ${ }^{44}$. Le 11 juillet 1818 , il signait un marché à cet effet avec les commissaires devant le notaire Jean Bélanger. Les travaux furent achevés à l'automne de la même année ${ }^{45}$.

Pour sa part, John Cannon fit une soumission de $£ 2350$ à la fois pour la construction du puisard et du canal, et pour l'érection d'un «pavillon en aile» contenant les «cellules morales» 46. Le 11 juillet 1818 , il s'engageait devant notaire à faire, pour les commissaires de l'Hôpital-Général, les travaux de maçonnerie, charpenterie, menuiserie, ferronnerie et vitrerie pour la seule construction d'un édifice à trois étages de 30 pieds de longueur sur 33 de profondeur, d'après les spécifications de l'architecte François Baillairgé ${ }^{47}$. Les dix pages de spécifications de ce dernier sont demeurées annexées au marché. Elles datent du 25 juin $1818{ }^{48}$. En janvier 1819, la construction de l'édifice était pratiquement terminée. Néanmoins, des modifications mineures apportées par Cannon au plan originel donnèrent lieu à des échanges de correspondance entre celui-ci et les commissaires, de même qu'entre ces derniers et les experts qu'ils avaient nommés, soit François Baillairgé et William Morrison, inspecteur des travaux au département des ingénieurs ${ }^{49}$. Après deux

43 Voir les pages 2 (en anglais) et 4 (en français). Les commissaires chargés des travaux étaient Joseph Planté, Thomas Wilson, Claude Denechau, William Holmes et François Durette.

44 AHGQ, Dossier «Différentes lettres», document n"101: Lettre de Chs Touchette, maître-maçon, à Joseph Planté, commissaire (22 juin 1818).

45 Archives nationales du Québec, Québec (dorénavant ANQ-Q), Greffe du notaire Jean Bélanger, Marché entre Charles Touchette, entrepreneur maçon, et Joseph Planté et les Commissaires de l'Hôpital-Général de Québec, 11 juillet 1818, no 7433. La quittance finale date du 19 novembre 1818.

46 AHGQ, Dossier «Différentes lettres», document no 102 : Lettre de

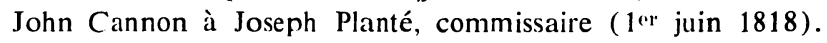

47 ANQ-Q, Greffe du notaire Jean Bélanger, Marché entre John Cannon, 'entrepreneur maçon, et Joseph Planté et les Commissaires de l'Hôpital-Général de Québec, 11 juillet 1818, no 7434.

48 Ce document fort intéressant s'intitule «Description des divers Ouvrages de la Batisse \& Reparations au Pavillon en Aile de la maison des Dammes de l'Hopital Général pour servir à la Confection du Marché à passer pour iceux.../faits a la Requisition du Sieur Th: Wilson Ecuyer un des Commiss"res par Fr». Baillairgé architecte.../Quebec le 25 juin 1818 ». 
examens, l'ouvrage fut jugé recevable par ces experts et une quittance finale fut signée le 23 septembre $1820^{50}$.

Le nouvel édifice était en pierre et coiffé d'un toit à deux versants percé de lucarnes. Chacun des deux étages en pierre était divisé par une allée éclairée par une grande ouverture et donnant de chaque côté sur trois loges ${ }^{51}$. Les subdivisions internes de l'édifice étaient en brique. Les cellules mesuraient 9 pieds de longueur sur 8 de largeur et elles avaient 9 pieds de hauteur ${ }^{52}$. Leur intérieur était recouvert de bois. Il y avait une ouverture pour servir les lunatiques et une fenêtre ferrée et vitrée à carreaux pour l'entrée de l'air et de la lumière. Chaque cellule disposait d'un évier pour l'écoulement des immondices ${ }^{53}$.

Un plan schématique, tracé par l'arpenteur Jean-Baptiste Larue, en 1827, et conservé aux archives de l'Hôtel de ville de Québec, nous permet de visualiser les emplacements respectifs des anciennes et des nouvelles loges (ill. 5). Par ailleurs, une photographie de ces dernières nous est heureusement parvenue grâce au daguerréotypiste L.A. Le Mire. Ce dernier les photographia en 1854, quelques années avant leur démolition. L'édifice des loges de 1818 apparaît à l'extrême droite de son daguerréotype, lequel est conservé à l'Hôpital-Général (ill. 6). Enfin, une aquarelle de James Patterson Cockburn exécutée vers 1830 et appartenant aux Ursulines de Québec nous donne une idée d'ensemble des édifices composant l'Hôpital-Général à cette époque. À gauche du personnage au premier plan, on aperçoit le corps principal du bâtiment et l'ancien moulin à vent de l'institution. À sa droite se trouvent la maison des employés (ou «engagés ») de l'hôpital et, à l'extrême droite, l'édifice des anciennes loges (ill. 7).

49 AHGQ, Dossier «Différentes lettres», document n 103 : Lettre de John Cannon aux Commissaires (20 juin 1820) ; no 104 : Lettre de François Baillairgé et William Morrison à Joseph Planté, commissaire (26 juillet 1820) ; n" 105 : Lettre de William Morrison à Joseph Planté, commissaire (24 février 1820 ).

50 Évalués à $£ 1375$ lors de la signature du marché, les travaux de Cannon coûtèrent au total $£ 15995$ sh. 3 p.

51 Tous les documents consultés mentionnent l'existence de seulement six loges dans le nouvel édifice. Il est donc possible que certains des appartements aient été utilisés à d'autres fins.

52 AHGQ, Journal (1760-1825), p. 350.

53 Voir La Gazette de Québec, 28 mai 1818, p. 4 et ANQ-Q, Greffe du notaire Jean Bélanger, Marché..., 11 juillet 1818, no 7434. 


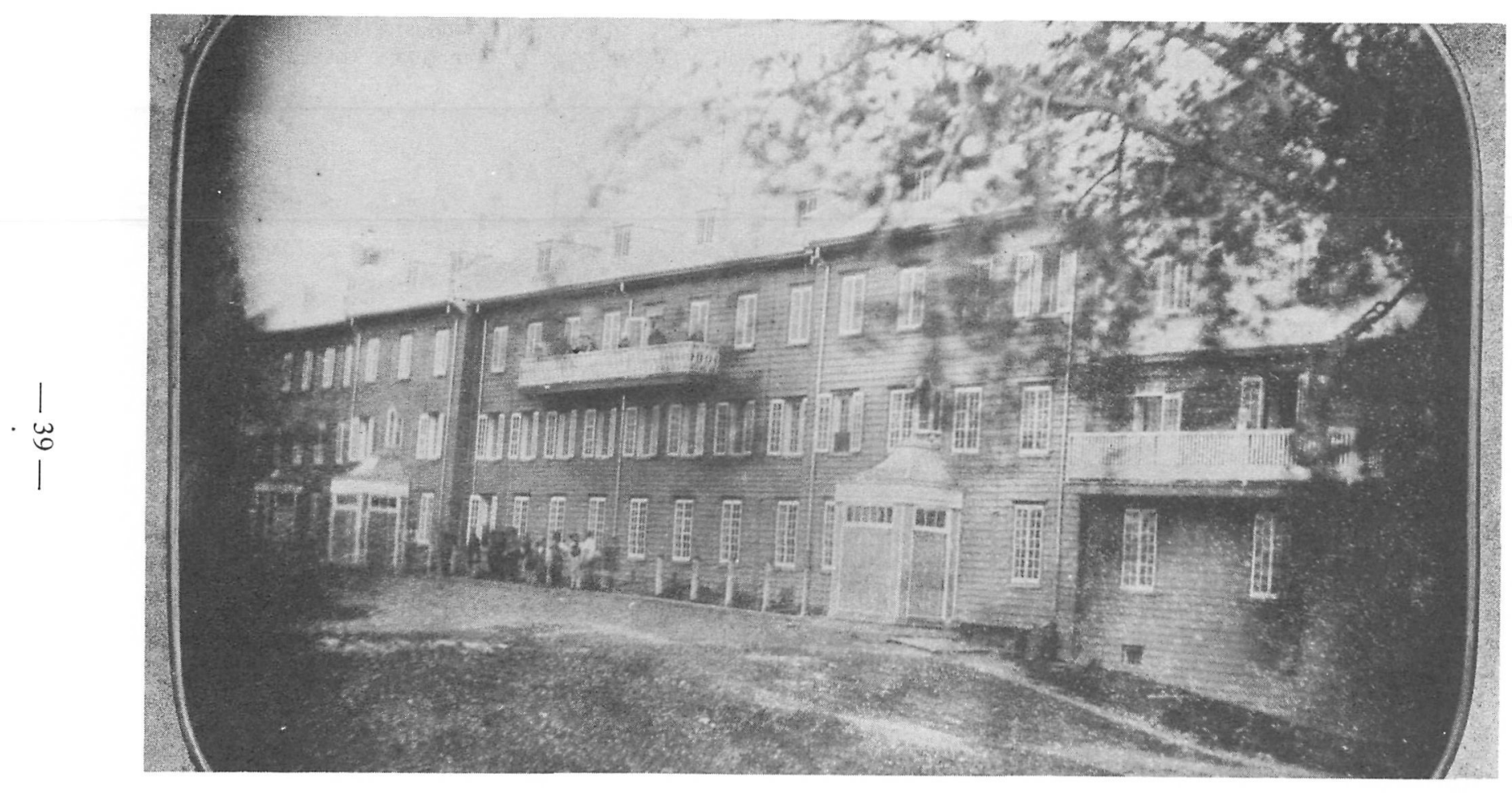

6. L.A. LE Mire, Façade de l'Hôpital-Général de Québec. - Daguerréotype pris en $1854.16,5 \times 21,6 \mathrm{~cm}$. Archives de l'Hôpital-Général de Québec, Québec. 


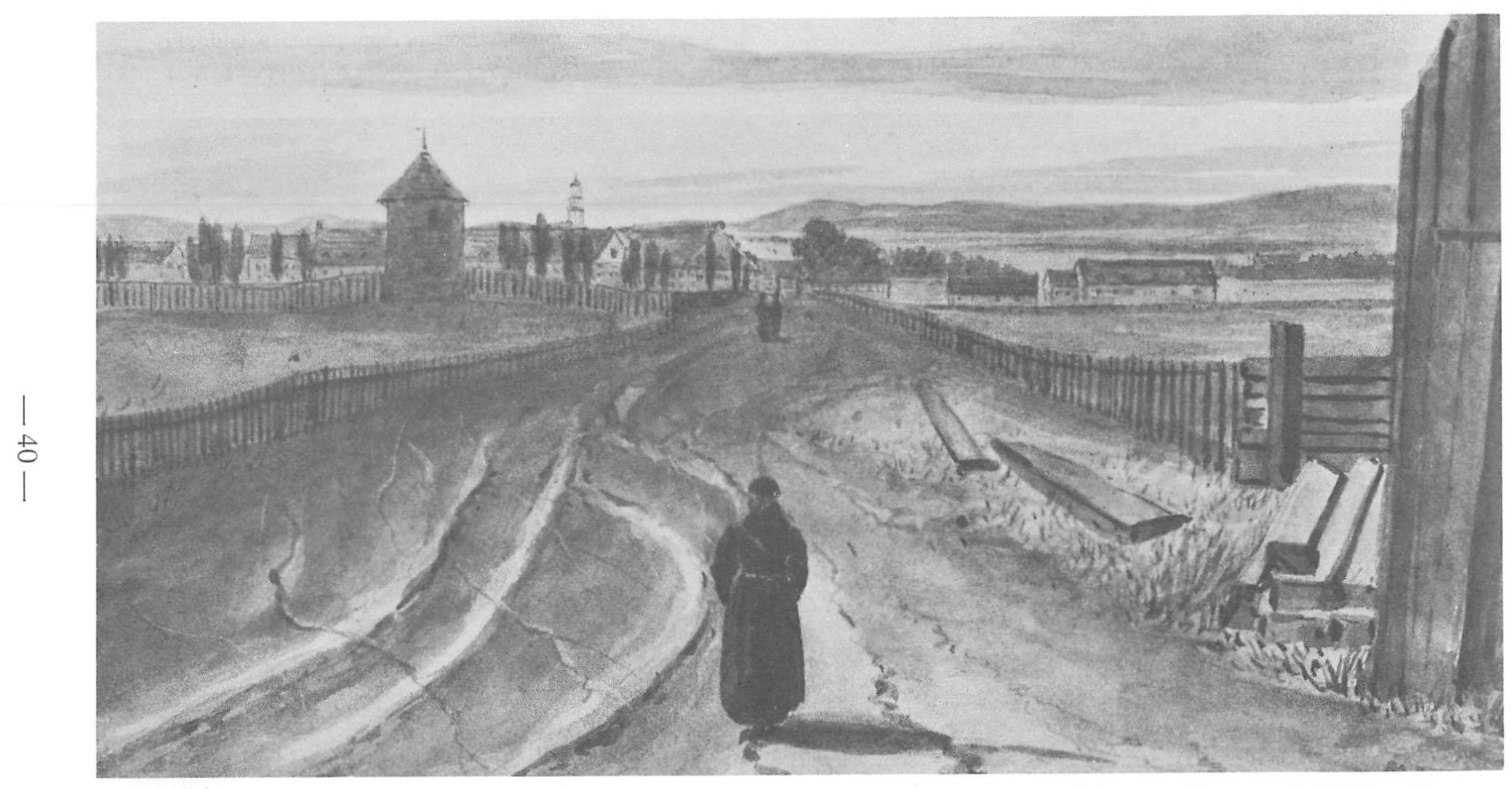

7. James Patterson Cockburn, General Hospital near Quebec. - Aquarelle exécutée vers 1830. $12,1 \times 20,5 \mathrm{~cm}$. Archives du Monastère des Ursulines, Québec. 
En 1821, une somme de $£ 336$ fut allouée pour l'exécution de travaux jugés indispensables à ces dernières. Ces fonds furent dépensés en 1822-1823 :

(...) la dite somme a été dépensée (...) à faire une clôture en cèdre de 300 pieds de long et d'environ douze pieds au dessus du niveau du terrain, afin d'isoler les 18 cellules dans un seul bâtiment; à faire un égout souterrain autour du dit bâtiment pour décharger les immondices dans la Rivière $S^{t}$ Charles; à réparer l'intérieur des cellules; à des portes et fenêtres neuves, \& et; à faire une nouvelle couverture en bardeaux et réparer le toit et les cheminées qui en avaient besoin, à faire une nouvelle bâtisse séparée du bâtiment où sont les cellules pour y loger la paille nécessaire aux Maniaques ${ }^{54}$, et à faire diverses autres réparations (...)

[Les] réparations et améliorations [...] ont presque doublé celles qu'on avait eues en contemplation, mais [...] elles étaient absolument nécessaires pour rendre l'établissement plus sain et plus commode 55 .

Ces travaux furent réalisés en majeure partie en 1822 par le maîtremenuisier Benjamin Moitard dit Lamothe 56 et par le maître-couvreur en bardeaux Louis Chevrette ${ }^{57}$.

C'est à la même époque, soit vers 1823 , que fut mis sur pied un comité spécial chargé de "s'enquérir et de faire rapport sur les établissements en cette Province pour la réception et la cure des Insensés, pour la réception et le soutien des enfants trouvés, et pour le soulagement et la guérison des pauvres malades et infirmes, avec les dépenses d'iceux défrayées à même le Revenu de la Province... ». Ce comité se composait des honorables Richardson, Cuthbert, Bell, Duchesnay et Coffin. Le Conseil législatif l'avait créé suite à de nombreux débats parlementaires relatifs à la question des subsides

54 Il s'agit peut-être du petit bâtiment adossé aux anciennes loges que l'on aperçoit dans le plan de Larue (ill. 5) et dans l'aquarelle de Cockburn (ill. 7).

55 AHGQ, Journal (1760-1825), pp. 349-350.

56 ANQ-Q, Greffe du notaire Antoine Archange Parent, Marché entre Benjamin Moitard dit Lamothe, maitre menuisier, et les commissaires pour le soulagement des personne's dérangées dans leur esprit, 4 juin 1822, no 2351. Pour plus de précisions sur les travaux effectués par Moitard, voir ce document. La quittance attachée à ce marché date du 18 octobre 1822 .

57 Ibid., Marché entre Louis Chevrette, maître couvreur en bardeaux, et les commissaires pour le soulagement des personnes dérangées dans leur. esprit, 5 juillet 1822, no 2409. Chevrette couvrit en bardeaux deux cellules et sept lucarnes. Il reçut $£ 424$ sh. pour son travail. 
octroyés aux maisons religieuses pour le soutien de leurs différentes œuvres. Certains s'étaient récriés devant « l'augmentation effrayante de ces dépenses ", croyant y voir un "encouragement à l'imprévoyance et à la paresse ${ }^{58}$. Le rapport du comité d'enquête fut publié le 10 février $1824^{59}$. Il ne mit à jour aucun abus dans l'emploi des deniers publics ${ }^{60}$. Toutefois, il rassembla des témoignages et des statistiques qui nous éclairent sur le traitement des aliénés au Bas-Canada et en particulier à l'Hôpital-Général de Québec.

Le témoignage du $\mathrm{D}^{\mathrm{r}}$ Holmes, médecin des religieuses de l'hôpital et membre de la Commission dont nous avons parlé plus haut, s'avère un des plus intéressants :

Il y a à l'Hôpital-Général pour les maniaques dix-huit cellules communes (...) et six cellules morales (...). Les cellules communes et morales sont bien chauffées. On n'a jamais recours à des mesures sévères à l'égard des internes, mais on employe la camisole de force, et la chaine lorsque ces moyens paroissent nécessaires à la protection et à la santé. Quand la situation des maniaques est telle que leur propre sureté et celle des autres le rend nécessaire on les tient enfermés jour et nuit, sans cela ils ne le sont pas.

Les maniaques recoivent un traitement médical pour leur guérison, selon Pinel de Paris, et Haslam de Londres. Les religieuses reçoivent les instructions nécessaires relatives à ce traitement. On pourroit rendre les cellules plus convenables au traitement médical, sur le plan perfectionné de structure des asiles et du traitement des maniaques en Europe, et surtout de celui de Glasgow.

Il y a un gardien pour les cellules destinées aux hommes, et une femme en fait les fonctions dans celles occupées par celles de son sexe, lesquels gardiens sont sous les ordres des médecins qui en sont chargés, et sous la direction des Religieuses quant à la nourriture qui leur convient; et avec l'assistance d'autres personnes quant la violence $\mathrm{du}^{-}$maniaque le rend nécessaire; ils changent de cellules afin de nettoyer celles qu'ils occupent 61 .

Le rapport révéla que, de 1800 à 1824, 207 aliénés avaient été admis dans les maisons de Québec, Montréal et Trois-Rivières.

58 AHGQ, Journal (1760-1825), p. 344 ; Monseigneur de Saint-Vallier..., op. cit., p. 498.

59 FerLAND-ANGers, op. cit., p. 357.

60 AHGQ, Journal (1760-1825), p. 345.

61 Ibid., pp. 350-351. 
Du nombre, 88 y étaient morts, 93 avaient été libérés et 26 étaient encore internés 62 . À Québec, 111 aliénés avaient été reçus dans les loges, soit 66 hommes et 45 femmes. En 1824, neuf hommes et sept femmes y étaient encore détenus ${ }^{63}$.

À l'Hôpital-Général de Montréal, 84 aliénés avaient été renfermés; six l'étaient encore en 1824. Précédemment, 29 personnes y étaient mortes, tandis que 49 autres avaient été libérées. En 1800, les Sœurs Grises avaient accepté les offres du gouvernement et la construction d'un édifice en pierre abritant huit loges avait été entreprise. Ces cellules mesuraient 8 pieds de longueur sur 6 pieds de largeur et elles avaient 7 pieds et 10 pouces de hauteur. Elles étaient, semble-t-il, fort peu salubres. En 1818, une somme de $£ 2000$ avait éié votée - comme à Québec - pour l'érection de cellules additionnelles et pour la réparation des anciennes. Les religieuses et le médecin attaché à l'institution, le $\mathrm{D}^{\mathrm{r}} \mathrm{Selby} \mathrm{Sr}$, avaient refusé cette somme, convaincus qu'elle ne servirait qu'à donner de l'ampleur à un système de réclusion jugé inapproprié. À partir de 1831, l'institution n'accepta plus de nouveaux patients mais garda ceux qu'elle avait déjà. En 1844, il n'en restait plus que deux. Entre-temps, les nouveaux aliénés furent enfermés à la prison de Montréal ${ }^{64}$. Une sépia exécutée par John Drake en 1826 et conservée dans les archives du Séminaire de Québec représente la façade de l'Hôpital-Général de Montréal (ill. 8). Entre le mur d'enceinte et la porte principale de la chapelle, on peut voir les loges construites en 1802 et démolies en $1844{ }^{65}$.

Nous en savons beaucoup moins sur les loges desservies par les Ursulines de Trois-Rivières. Au nombre de six, elles furent bâties en 1808 pour recevoir les aliénés de la ville et des environs. Elles mesuraient 8 pieds sur 6 et avaient 8 pieds de hauteur. Les conditions de détention y étaient, dit-on, pitoyables, l'usage des fers et des camisoles de force étant chose courante ${ }^{66}$. Elles furent démolies le 13 avril 1908. Une photographie nous en est parvenue, qui illustre bien le système primitif de réclusion des aliénés à l'époque (ill. 9). Une petite ouverture munie de barreaux était la seule source de lumière et d'aération dont disposait chaque interné.

62 Maude E. Аввотт, History of Medicine in the Province of Quebec, Toronto, Macmillan, 1931, p. 77.

63 AHGQ, Journal (1760-1825), p. 346.

64 Аввотt, op. cit., p. 77 ; FerLand-ANGers, op. cit., p. 357.

65 Ferland-Angers, op. cit., p. 96X.

66 Аввотт, op. cit., pp. 77-78. 


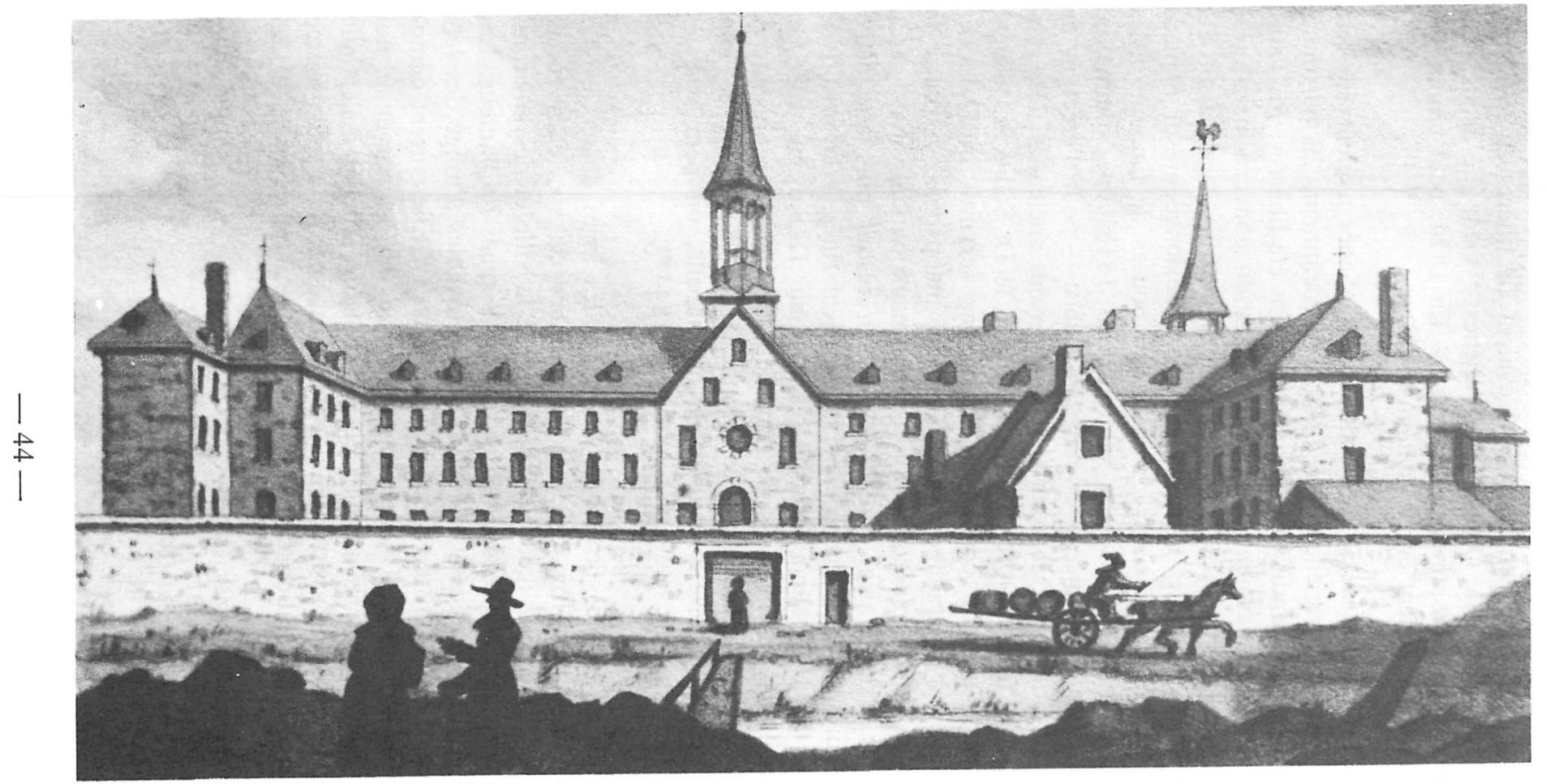

8. John Drake, L'Hôpital-Général de Montréal. - Sépia exécutée en 1826. 10,8 × 16,5 cm. Archives du Séminaire de Québec, Québec. Photo: Inventaire des biens culturels du Québec, Québec. 


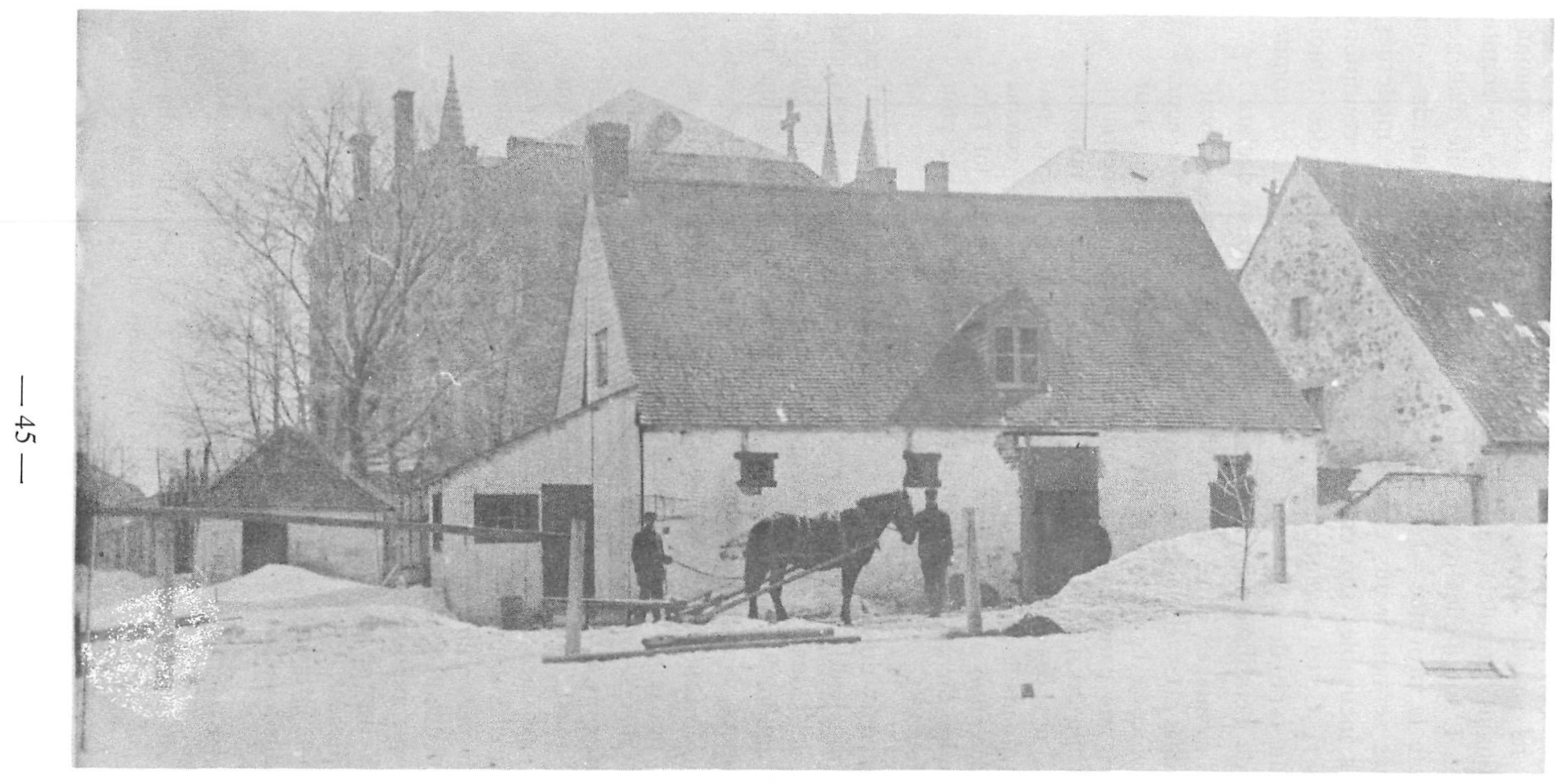

9. Les loges desservies par les Ursulines de Trois-Rivières. - Photographie prise avant le 13 avril 1908 et dont l'original est conservé au Monastère des Ursulines de Trois-Rivières. Photo: Inventaire des biens culturels du Québec, Québec. 
On ne saurait donc s'étonner de la vigueur des recommandations finales formulées en février 1824 par les membres du comité d'enquête. L'une d'elles réclamait la construction d'un asile d'aliénés pour toute la province - ou pour le Haut et le Bas-Canada - où les aliénés seraient reçus et soignés selon des méthodes modernes, et où les incurables seraient gardés dans les meilleures conditions possibles ${ }^{67}$. Cette résolution s'appuyait sans doute sur des témoignages du type de celui que fit le $\mathrm{D}^{\mathrm{r}}$ Hackett devant le comité. Parlant de l'établissement d'un asile central, celui-ci déclara :

Les avantages d'une telle institution sont immenses, incalculables; les établissements aujourd'hui destinés dans cette Province à la réception des personnes dérangées dans leur esprit me paraissent plutôt propres à entretenir l'aberration casuelle des facultés mentales incidente à la nature humaine sous des circonstances particulières; le mal peut être peu grave dans le principe, mais des causes secondaires, - comme la détention dans des lieux si misérables, - peuvent lui faire prendre un caractère tout-à-[fait] différent et la fixer pour toujours 68 .

Les vœux du $\mathrm{D}^{\mathrm{r}}$ Hackett et du comité d'enquête allaient rester lettre morte pendant plus de vingt ans. En janvier 1844, le GrandJury de la Cour des sessions de la paix du district de Québec revenait encore à la charge dans le cadre d'un Rapport rédigé par son président, Napoléon Aubin :

Dans le cours de nos visites nous avons pu regretter qu'il ne soit pas érigé un hospice convenable et uniquement destiné aux aliénés, où un genre de traitement plus nouveau, plus doux, plus éclairé pourrait être suivi. L'établissement des aliénés sous les soins des pieuses dames de l'Hopital-Général, qui est aussi bien conduit que le permettent le local et les moyens dont elles disposent, regorge de malades; la plupart des salles de la prison en contiennent plusieurs, et d'après la disposition particulière des édifices il est évident que la guérison y est presque impossible, tandis que les systèmes récemment adoptés en Europe et en diverses parties des Etats-Unis prouvent que la douceur, la distraction, le travail même, rendent la raison à des infortunés que la détention dure et solitaire aurait perdus à jamais 69 .

67 Loc. cit. ; AHGQ, Journal (1760-1825), p. 351 (commentaire du Dr Holmes).

68 AHGQ, Journal (1760-1825), p. 351. Le Dr Hackett déposa devant le comité une copie du mémoire qu'il avait soumis au gouverneur Sherbrooke en 1816.

69 Le Castor de Québec, 30 janvier 1844, p. 3. 
Le gouverneur, Sir Charles Metcalfe, s'était préoccupé de la question d'un nouvel asile central depuis son arrivée en 1843. Le rapport du Grand-Jury ayant mis en lumière l'urgente nécessité d'une telle institution, il conclut, en 1845, une entente avec le $D^{r}$ James Douglas de Québec, afin que ce dernier se charge du soin des aliénés de la province pour une période de trois ans, l'érection d'un nouvel édifice devant s'effectuer dans l'intervalle. En attendant, Douglas s'associa au $D^{r}$ Fremont et au $D^{r}$ Morrin, et tous trois se préparèrent à accueillir les aliénés de toute la province dans l'ancien manoir seigneurial de Beauport converti en asile. Ce dernier fut aménagé pour recevoir jusqu'à 120 personnes avec les gardiens nécessaires ${ }^{70}$. Les préparatifs étant achevés, Metcalfe ordonna que les aliénés à la charge du Gouvernement dans les districts de Québec, Montréal et Trois-Rivières soient transférés à l'Asile temporaire de Beauport à l'automne de $1845{ }^{71}$.

À l'Hôpital-Général de Québec, on accueillit avec satisfaction la décision gouvernementale. En août 1845, les religieuses se penchèrent sur une proposition $\mathrm{du} \mathrm{D}^{\mathrm{r}}$ Joseph Morrin ayant trait au transfert des aliénés :

Le 17 août, la Mère Supérieure a fait assembler les Discrètes, pour décider si nous pouvions nous retirer du service des aliénés placés dans les loges extérieures, voyant les inconvénients et les difficultés qu'apporte la desserte de cette partie de notre Hôpital, tant pour les soins personnels que nous ne pouvons leur donner, ni leur faire donner et que leur état exige, que pour la raison que les loges sont situées hors de l'enceinte de la clôture. D'après ces raisons et plusieurs autres semblables appuyées de l'approbation de Mgr. notre Supérieur, qui approuve fort que nous soyons déchargées de cette besogne. En conséquence il a été résolu que nous donnerions une information affirmative au $D^{r} J$. Morrin, Directeur de l'asile des aliénés à Beauport, afin de fixer l'époque de leur transport 72 .

70 Аввотт, op. cit., p. 78 ; AHGQ, Journal (1825-1867), p. 121 ; Roy, op. cit., p. 143.

71 AHGQ, Journal (1825-1867), p. 123 ; АввотT, op. cit., p. 78. En septembre et octobre 1845, l'Asile temporaire de Beauport accueillit un grand total de 81 aliénés venant de Québec (Hôpital-Général), Montréal (prison) et Trois-Rivières (Ursulines).

72 AHGQ, Actes des discrètes, tome I (1838-1940), pp. 21-22. 
La relation du transfert des aliénés de Québec à Beauport nous est parvenue :

Le 15 de septembre 1845 à six heures du matin les aliénés - six hommes et six femmes 73 - aux soins des Dames Religieuses de l'Hôpital-Général de Québec furent amenés à l'Asýle. Les medecins présents éprouvèrent un vif intérêt dans le transport de ces infortunés. Un d'eux avait été renfermé au delà de 28 ans, plusieurs au delà de 20 ans, et les autres pendant un laps de temps plus ou moins court. Pendant tout ce temps ils avaient été séquestrés dans des loges séparées, dans une bâtisse à un étage de peu de hauteur, entourée d'une forte clôture en cèdre de 12 pieds. Jamais on ne leur avait permis de sortir de la bâtisse, et la plupart avaient été constamment tenus dans leurs loges. Rarement voyaient-ils quelque personne, à moins que ce ne fut la visite périodique des Grands Jurés et les personnes chargées de pourvoir à leurs besoins. La plupart de ces malades avaient des habitudes de malpropreté dégoutante ; plusieurs étaient considérés dangereux, et les autres étaient tombés dans un étât d'imbécilité ou de démence ${ }^{74}$.

L'arrivée des Médecins avec les cabs leur causa une nouvelle sensation et Les Docteurs J. Douglas, J. Morrin, C. Frémont et Jos. Painchaud se partagèrent dans les quatre voitures et y firent monter les aliénés qui ne firent aucune résistance. Voici comment ces Messieurs ont rendu compte de cette translation :

(...) Ils furent transportés dans des voitures à quatre roues. Ils furent charmés de la promenade ; la vue de la ville, du fleuve, des arbres, et des passants parut leur procurer les émotions les plus agréables. A leur arrivée à l'Asile, on les plaça tous ensemble à la table pour déjeuner. C'était un spectacle des plus intéressant, que d'etre témoin de leur bonne conduite, d'épier leurs actions et de remarquer l'étonnement que leur causait tout ce qui les environnait. Dans un moment toute trace de férocité et de vacarme avait disparu. Un d'eux (...) homme de talent et de quelque éducation errait d'une fenêtre à l'autre, il regarda Québec et reconnut une ville

73 Le nombre d'aliénés transférés de l'Hôpital-Général à l'asile de Beauport est controversé. On mentionne ici six hommes et six femmes alors que dans le Registre des Aliénés de l'Hôpital-Général on dénombre huit hommes ( $n^{\text {os }} 77,122,166,179,206,213,216$ et 218) et six femmes (nos 182, 184, 186, 219, 220 et 221). Par ailleurs, Аввотт (op. cit., p. 78) évalue à 23 le nombre d'aliénés transférés de Québec à Beauport.

74 AHGQ, Journal (1825-1867), pp. 123-124. 
et les vaisseaux sur le fleuve, mais ne put comprendre ce qu'étaient les bateaux à vapeur... ${ }^{75}$.

Il fallut peu de temps pour constater les effets bénéfiques qu'eut sur les aliénés ce transfert à Beauport :

Quand les malades eurent recouvré suffisamment leurs forces, ils furent induits à s'occuper de la manière qui leur était agréable ou conforme à leurs anciennes habitudes. Quelques uns travaillèrent dans le jardin, d'autres préférèrent scier et fendre du bois, \&et. On fit sortir les femmes tous les jours, et plusieurs s'amusèrent à sarcler dans le jardin. On s'aperçut, bientôt, des bons effets de ce système. Leur santé s'améliora, et ils parurent prendre de la gaité et du contentement. Ils reprirent plus de forces, mangèrent et dormirent mieux. Queiques uns furent ramenés à la raison. Un d'eux qui avait été enfermé dans les loges de l'Hôpital-Général pendant plusieurs années après 13 mois de séjour à l'Asyle, fut gueri et rendu à sa famille et à la société. Une fille qui avait aussi été enfermée pendant plusieurs années, se rétablit après 14 mois, et s'engagea comme institutrice à la campagne. L'étât des autres malades généralement, quoique amélioré, laissait peu d'espoir de guérison... ${ }^{76}$.

Après le départ des aliénés, les anciennes loges du régime français et celles construites en 1802 furent utilisées comme décharges pour le bois de chauffage. En mauvais état et de dimensions insuffisantes, elles furent démolies en 1857 pour faire place à un grand hangar à bois ${ }^{77}$. Quant à l'édifice des "cellules morales 》 bâti en 1818, il avait, depuis 1845, servi à accueillir les invalides les plus infirmes de l'institution. Comme il était peu salubre et que les autorités de l'Hôpital-Général envisageaient la construction d'une nouvelle aile sur son site, on le démolit en $1859^{78}$.

Nous avons pu dénombrer 282 aliénés accueillis à l'HôpitalGénéral de Québec avant 1845, soit 158 hommes et 124 femmes ${ }^{79}$.

75 AHGQ, Notes diverses, 1686-1866, pp. 194 et 196.

76 AHGQ, Journal (1825-1867), p. 125 ; Аввотт, op. cit., p. 78 . Sur les suites de l'Asile temporaire de Beauport, voir Aввот,, op. cit., p. 78 et suivantes, et RoY, op. cit., pp. 143-144.

77 AHGQ, Actes capitulaires, tome II (1821-1858), p. 121 ; Journal (1825-1867), p. 121 ; Journal du dépôt, tome I (1692-1909), p. 270 ; Notes diverses, 1686-1866, p. 471.

78 AHGQ, Actes capitulaires, tome III (1859-1922), pp. 5-6; Journal (1825-1867), p. 393.

79 Dans ses Notes historiques (p. 19) conservées aux AHGQ, Mère Saint-Alphonse évalue à 264 le nombre d'aliénés admis de 1776 à 1845 . Nous avons expliqué comment nous avons procédé à notre dénombrement dans la note 18. C'est pourquoi notre évaluation diffère. 
Cette évaluation est bien sûr minimale et imparfaite puisque nous ignorons combien de patients furent internés entre 1717 et 1776. Sur ces 282 aliénés, nous avons relevé autant de noms à consonnance française [132] que de noms à consonnance anglaise [132]. Neuf Irlandais sont identifiés comme tels tandis qu'on compte trois " nègres », deux Allemands, deux Français, un Amérindien et un Juif. De plus, les loges accueillaient autant les protestants que les catholiques.

Si l'on excepte quelques étrangers, la plupart des aliénés venaient de Québec et des paroisses environnantes : Saint-Roch [4], SainteFoy, Ancienne-Lorette, Loretteville, La Canardière, Charlesbourg et Beauport. Sur la rive nord, il en vint aussi de Deschambault, Pointe-aux-Trembles et Saint-Augustin en amont de Québec, et de Saint-Pierre (Île d'Orléans) et Baie Saint-Paul en aval. Sur la rive sud, nous en avons relevé venant de Pointe-Lévy (Lauzon) [4] et de paroisses situées plus au sud, telles Saint-Henri, Saint-Gervais [2], Sainte-Claire et Saint-Sylvestre. En aval de Lauzon, il en vint de Beaumont [5], Saint-Michel, Saint-Vallier, Saint-Thomas de Montmagny [2], Saint-Pierre de Montmagny, Cap Saint-Ignace, et même de Rivière-Ouelle et Saint-Pascal de Kamouraska. On mentionne également un aliéné venu des «postes d'en bas». Enfin, quatre internés vinrent de Montréal, peut-être à cause de l'insuffisance des loges de cette ville.

Le métier exercé par l'aliéné avant son internement n'est pas toujours mentionné dans les registres. En fait, on ne spécifie que celui de 31 hommes sur 158 . Si le relevé que nous en avons fait n'est qu'indicatif, il nous démontre en revanche que toutes les classes sociales étaient touchées par l'aliénation mentale. Ainsi, avons-nous compté un médecin, un avocat, deux officiers, sept soldats, un capitaine de navire, un pilote, deux matelots, deux marchands, un aubergiste, cinq cultivateurs, deux forgerons, un charron, un menuisier, un cordonnier, un jardinier et deux journaliers. Treize veuves sont identifiées comme telles. On compte également un fils de juge et un fils d'écrivain ${ }^{80}$.

La durée de séjour de l'aliéné était extrêmement variable. Elle pouvait aller d'une nuit à plus de quarante ans. Un très grand nombre de malades entrèrent dans les loges pour moins d'une année.

80 Parmi les aliénés, on relève $X$ fils, fille ou épouse : d'écuyer (1), de marchand (2), de cultivateur (9), d'encanteur (1), de forgeron (1), de maçon (1), de menuisier (2), de scieur de long (1), de charretier (2), de cordonnier (2), de tailleur (1), de journalier (6). 
Plusieurs n'y restèrent que quelques jours. Certains y moururent peu de jours après leur admission, voire même le lendemain. Une aliénée turbulente fut admise à six reprises entre 1797 et 1800 ; elle devait mourir dans les loges en 1802. En 1815, un jeune garçon âgé de sept ans fut interné pour une période de six mois. Par contre, une Amérindienne s'éteignit dans les loges à l'âge de 116 ans, après douze ans d'internement ${ }^{81}$.

Le gouvernement assumait généralement les frais de pension des aliénés. On se rappellera qu'avant 1800 , il le faisait sous le régime de pension des invalides. Sur les 237 internements relevés après 1800,203 furent couverts par le gouvernement sous le nouveau régime de pension des aliénés. Les pensions des autres malades étaient surtout payées par les familles mais parfois aussi par un curateur, un prêtre ou par le malade lui-même.

Le système de renfermement des aliénés au Québec n'évolua guère de 1717 à 1845 . Dans son ensemble, il demeura archaïque au grand détriment de la santé morale et physique des aliénés. Peu ou pas de distinctions étaient faites entre ceux-ci, quelle que fût la gravité de leur maladie. L'éventail des appellations par lesquelles on les désignait démontre pourtant la variété des cas : «fous, aliénés, maniaques, insensés, furieux, imbéciles, déments, épileptiques, lunatiques, personnes dérangées dans leur esprit », etc. Les efforts de quelques médecins amenèrent bien sûr le gouvernement à poser certains gestes après bien des hésitations. Ceux-ci furent hélas tout à fait insuffisants. Contentons-nous de rappeler que, dans toute la province, seulement six "cellules morales 》 pouvaient accueillir des aliénés dont on espérait obtenir la guérison par des méthodes et dans un contexte appropriés.

Le maintien et la prolifération de loges de type conventionnel héritées du régime français, de par leur configuration, empêcha pratiquement les médecins d'appliquer les méthodes thérapeutiques requises. Ceux qui avaient tracé et maintenu le plan de ces loges «paraissent en effet n'avoir eu d'autres vues que de retirer de la société des personnes qui lui sont nuisibles par suite de l'aliénation de leur esprit ${ }^{82}$. Dans bien des cas,

81 Autre cas intéressant, celui de Benjamin Fowler qui, après avoir été soigné comme aliéné, construisit une pompe à eau pour les religieuses en 1834, peu après sa guérison. AHGQ, Actes capitulaires, tome II (18211858), pp. 11-12.

82 AHGQ, Notes diverses, 1686-1866, pp. 197. 
aucun moyen n'était employé pour leur faire retrouver leur raison perdue. Enfermées dans des cellules séparées, toute communication avec le monde extérieur ou entre elles, leur était interdite, et, livrées à l'action de leur imagination désordonnée, leurs facultés, d'après une loi constante de la nature, devenaient émoussées ou perdues faute d'être cultivées; puis elles tombaient dans un état d'exaltation délirante, déchiraient leurs vêtements, prenaient des habitudes de malpropreté dégoutante et finissaient par tomber dans un état de démence ou d'imbécilité ${ }^{83}$.

«La défectuosité générale de ces réceptacles, l'étât nécessairement malprophe des loges, leur manque de ventilation suffisante, leur humidité et le traitement général que recevaient les malheureux qui y étaient détenus » firent l'objet de vives et fréquentes réclamations de la part des médecins et des grands jurés au cours de la première moitié du XIX ${ }^{\mathrm{e}}$ siècle ${ }^{84}$.

Ces personnes, nous l'avons vu, étaient pour la plupart au courant du renouveau des méthodes de traitement des aliénés en Europe et notamment en France. Avant la Révolution, l'HôpitalGénéral de Paris gardait nombre d'aliénés. Ceux-ci étaient regardés d'avance comme incurables et ne recevaient pas de soins médicaux. "Ils habitaient des loges fétides, en contre-bas du sol, où la lumière et l'air n'entraient que par la porte [...] Lorsqu'ils devenaient furieux, on les mettait aux fers $\gg{ }^{85}$. Plusieurs des cahiers de doléance des États généraux de 1789 souhaitaient l'amélioration des méthodes de traitement des aliénés et la création d'asiles spéciaux. Dans l'un de ces cahiers, on pouvait lire :

On s'occupera plus sérieusement qu'on ne l'a fait jusqu'ici dans les hôpitaux de l'art de guérir les maniaques. On croit avoir tout fait quand, en les resserrant dans des réduits obscurs, capables d'altérer la raison de l'homme le mieux constitué, on les a mis hors d'état de nuire à leurs semblables ${ }^{86}$.

Dès 1791, on commença à envoyer à l'hospice les aliénés susceptibles de guérir. Leur situation s'améliora et bientôt elle se transforma complètement grâce à l'action de Philippe Pinel (1745-

83 AHGQ, Journal (1825-1867), p. 122.

84 Loc. cit.

85 Camille Bloch, L'assistance et l'état en France à la veille de la Révolution, Paris, Librairie Alphonse Picard et Fils, 1908, p. 86.

86 Ibid., p. 412; sur l'Histoire de la folie à l'âge classique, voir le brillant ouvrage de Michel Foucault publié à Paris (Librairie Plon) en 1961. 
1826). Ce médecin aliéniste substitua la douceur à la violence dans le traitement des maladies mentales. Il libéra les aliénés de leurs fers ${ }^{87}$. Ceux-ci ne furent plus enfermés comme des malfaiteurs. Les loges furent progressivement supprimées et l'on préconisa «un régime de vie commune pour les malades qui seraient occupés à des travaux rappelant leurs anciennes habitudes ». Seules quelques cellules servaient à l'isolement des violents. La loi du 30 juin 1838 imposa à chaque département l'obligation de posséder un établissement pour ces aliénés et fixa les conditions d'internement ${ }^{88}$.

Accusant un sérieux retard par rapport aux réformes européennes de Pinel, Tuke et Connolly ${ }^{89}$, la situation de l'aliéné au Québec ne connut un début d'amélioration qu'à partir de l'automne 1845. Les pressions des médecins, des grands jurés et des religieuses 90 étaient enfin venues à bout des lenteurs d'une administration qui avait trop longtemps préféré les cataplasmes aux mesures qui s'imposaient.

Dans tout ceci, les religieuses responsables des aliénés dans les districts de Québec, Montréal et Trois-Rivières auront joué un rôle ingrat, fastidieux et effacé, acceptant de prendre en charge ceux que la société laissait pour compte. À cet égard, il faut rappeler ici le témoignage éloquent que faisait le $D^{r}$ William Hackett sur le travail des Augustines de l'Hôpital-Général de Québec dans son mémoire au gouverneur Sherbrooke en 1816 :

Votre Excellence voudra bien me permettre de rendre témoignage du zèle avec lequel, à ma propre connaissance, ces Dames s'efforcent sans cesse de contribuer au bien-être et à la propreté des malheureux Maniaques commis à leurs soins, quelque désagréable et pénible que soit ce devoir ${ }^{91}$

John R. Porter, M.A.

Conservateur adjoint

de l'art canadien ancien,

Galerie nationale du Canada, Ottawa.

87 Georges Guillain et P. Mathieu, La Salpêtrière, Paris, Masson et Cie, 1925 , pp. 32 et 49.

88 Louis Hauteceur, Histoire de l'architecture classique en France, Paris, A. et J. Picard, 1948-66, tome VI [ « La restauration et le gouvernement de juillet 1815-1848»], p. 97.

89 Аввотт, op. cit., p. 75.

90 AHGQ, Journal (1825-1867), p. 122.

91 AHGQ, Journal (1760-1825), p. 352. 


\section{BIBLIOGRAPHIE}

\section{ARCHIVES ET SOURCES MANUSCRITES}

\subsection{ARCHIVES DE L'HÔPITAL-GÉNÉRAL DE QUÉBEC, QUÉBEC}

- Actes capitulaires, tome I (1699-1822), 250 pages ; tome II (1821$1858), 130$ pages; tome III (1859-1922), 432 pages.

- Actes des discrètes, tome I (1838-1940), 543 pages.

- Annales ["Suite des annales des Religieuses de La miséricorde de jesus. Etablie à notre Dame des anges près Québec »] (1709-1729), 84 pages.

- Annales des Religieuses Hospitalières de la Miséricorde de Jésus..., tome III (1794-1843), pagination incomplète.

- Copies de lettres adressées à Nos Communautés de France (17581935), 821 pages et autres non paginées.

- Dossier «Différentes lettres», documents 96 à 105 :

- 4 février 1817 : Lettre de Mor J.O. Plessis, évêque de Québec, à la supérieure de l'Hôpital-Général (no 98);

- 16 février 1817 : Lettre de Mgr J.O. Plessis, évêque de Québec, à la supérieure de l'Hôpital-Général (no 97) ;

- 25 février 1817 : Lettre des Commissaires aux religieuses de l'Hôpital-Général (no 100);

- 25 février 1817 : Lettre de Mrr J.O. Plessis, évêque de Québec, à Mère Sainte-Hélène, supérieure de l'Hôpital-Général de Québec (no 96);

- [25 février 1817] : Copie d'une lettre des religieuses de l'HôpitalGénéral aux Commissaires ( $n^{0}$ 99) ;

- $1^{\text {er }}$ juin 1818 : Lettre de John Cannon à Joseph Planté, commissaire (no 102);

- 22 juin 1818 : Lettre de Chs Touchette, maître-maçon, à Joseph Planté, commissaire (no 101) ;

- 24 février 1820 : Lettre de William Morrison à Joseph Planté, commissaire ( $\mathrm{n}^{\mathrm{o}}$ 105) ;

- 20 juin 1820: Lettre de John Cannon aux Commissaires (nv 103 ) ;

- 26 juillet 1820 : Lettre de François Baillairgé et William Morrison à Joseph Planté, commissaire ( no 104).

- Dossier «Divers documents», chemise «Aliénés》:

- Lettre de Sœur Sainte-Hélène, dépositaire, aux Commissaires, 27 octobre 1812.

- Entrées des pauvres et des Demoiselles pensionnaires Depuis 1773 jusqu'à 1833, registre non paginé.

- Journal: 1760-1825, 559 pages ; 1825-1867, 503 pages.

- Journal de la Dépense et recette depuis 1808 jusqu'à 1827, 371 pages (bis) [les comptes de la recette vont jusqu'au 25 avril 1827 et ceux de la dépense jusqu'au 31 août 1825].

- Journal du dépôt, tome I (1692-1909), 446 pages.

- Livres de comptes: 1727-1750, pagination incomplète ; 1804-1824, 223 pages doubles.

- Notes diverses, 1686-1866, 646 pages. 
- Notes historiques sur notre Etablissement par Mère Saint-Alphonse, 1950 , calepin de 65 pages.

- Registre des Aliénés reçus sur les pensions allouées par le Gouvernement à l'Hôpital-Général de Québec, non paginé [39 pages], suivi du Registre des Aliénés reçus en qualité de pensionnaire à l'HôpitalGénéral [8 pages]. Ce registre couvre la période 1776-1845.

\subsection{ARCHIVES NATIONALES DU QUÉBEC, QUÉBEC}

\section{GREFFES DES NOTAIRES}

- BÉlANGer (Jean), Marché entre Charles Touchette, entrepreneur maçon, et Joseph Planté et les Commissaires de l'Hôpital-Général de Québec, 11 juillet 1818, nu 7433.

- - Marché entre John Cannon, entrepreneur maçon, et Joseph Planté et les Commissaires de l'Hôpital-Général de Québec, 11 juillet 1818, no $^{\circ} 7434$.

- Parent (Antoine Ârchange), Marché entre Benjamin Moitard dit Lamothe, maître menuisier, et les commissaires pour le soulagement des personnes dérangées dans leur esprit, 4 juin 1822, no 2351.

- - - Marché entre Louis Chevrette, maître couvreur en bardeaux, et les commissaires pour le soulagement des personnes dérangées dans leur esprit, 5 juillet 1822, no 2409.

\subsection{ARCHIVES PUBLIQUES DU CANADA, OTTAWA}

- Série C.11a : vol. 41 , pp. $262-263$; vol. 42 , pp. 10v-12 ; vol. 43, pp. 3-4 et 383-386 ; vol. 44 , pp. $285 \mathrm{v}-286$; vol. 45 , p. $81 \mathrm{v}$.

2. SOURCES IMPRIMÉES (JOURNAUX)

- "Aux entrepreneurs de bâtisses» dans La Gazette de Québec, 28 mai 1818, page 4. Paru en anglais dans la même édition, à la page 2 , sous le titre "To Undertakers of building 》.

- "District de Québec. Cour des sessions trimestrielles de la paix. Rapport du Grand-Jury» dans Le Castor de Québec, 30 janvier 1844, p. 3.

\section{3. ÉTUDES (LIVRES ET ARTICLES)}

- Aввотт (Maude E.), History of Medicine in the Province of Quebec, Toronto, Macmillan, 1931, 97 pages.

- Bloch (Camille), L'assistance et l'état en France à la veille de la Révolution, Paris, Librairie Alphonse Picard et Fils, 1908, 504 pages.

- D'Allaire (Micheline), L'Hôpital-Général de Québec, 1692-1764, Montréal, Fides [1971], 251 pages.

- Ferland-Angers (Albertine), Mère d'Youville, Vénérable MarieMarguerite du Frost de Lajemmerais, veuve d'Youville, 1701-1771, Fondatrice des Saurs de la Charité de l'Hôpital-général de Montréal dites Saurs Grises, Montréal, Beauchemin, 1945, 389 pages.

- Guillain (Georges) et P. Mathieu, La Salpêtrière, Paris, Masson et Cie, 1925, 87 pages.

- Hautecceur (Louis), Histoire de l'architecture classique en France, Paris, A. et J. Picard, 1948-66, 7 volumes.

- Monseigneur de Saint-Vallier et l'Hôpital Général de Québec, Québec, C. Darveau, 1882, 743 pages.

- Roy (Pierre-Georges, "Les asiles d'aliénés», dans Bulletin des recherches historiques, vol. I, no 9 (septembre 1895), pp. 143-144. 